\title{
AVALIAÇÃO NORMATIVA DO PROGRAMA PPSUS: UM ESTUDO DE CASO NO ÂMBITO DO CNPq
}

Normative Assessment of PPSUS Program: a Case Study at CNPq

\author{
Suzana Rachel de Oliveira ${ }^{1}$ \\ Carolina Bittencourt Gomes ${ }^{2}$ \\ Luciana Calabró ${ }^{3}$
}

\begin{abstract}
Resumo: O Programa Pesquisa para o SUS: gestão compartilhada em saúde (PPSUS), uma das políticas de fomento descentralizado do CNPq, busca a redução das desigualdades em ciência, tecnologia e inovação em saúde, por meio do financiamento de pesquisas em linhas prioritárias definidas por cada Unidade da Federação. O objetivo do estudo é realizar uma avaliação normativa do PPSUS, no âmbito do CNPq, e estimar o seu grau de implantação, baseada em critérios/indicadores e parâmetros orientados pela construção do modelo lógico e validados pela técnica Conferência de Consenso. Foi realizado um estudo de caso. Os dados foram coletados por meio das técnicas de análise documental e de observação participante. Os resultados mostraram que o grau de implantação dos componentes estrutura e processo foram, respectivamente, $66,66 \%$ e $84,21 \%$. Os resultados indicam que o programa apresenta implantação satisfatória, porém com necessidades de melhorias na gestão do fomento.
\end{abstract}

Palavras-chave: Avaliação normativa. Fomento descentralizado. PPSUS.

Abstract : PPSUS, one of CNPq's decentralized funding policies, aims to reduce inequities on science, technology and innovation in the health sector through funding priority researches on health care themes defined by each Federation Unity. This study aims to realize a normative assessment and verify the implantation degree of PPSUS at CNPq based on criteria / indicators and parameters guided by the construction of the logical model and validated by the Consensus Conference technique. It was performed a case study. Data were collected using document analysis and participant observation techniques. Results showed that the implantation degree in structure component was $66,66 \%$ and $84,21 \%$ in process component. It indicates a satisfactory implantation of PPSUS, but it needs improvement in funding management.

Keywords: Normative assessment. Decentralized funding. PPSUS

\footnotetext{
${ }^{1}$ Doutoranda do Programa de Educação em Ciências da Universidade Federal do Rio Grande do Sul (UFRGS), Analista em Ciência e Tecnologia do Conselho Nacional de Desenvolvimento Científico e Tecnológico (CNPq), Orcid: https://orcid.org/0000-0002-3275-9199, e-mail: suzanarachelo@gmail.com.

${ }^{2}$ Mestranda do Programa de Educação em Ciências da UFRGS. Especialista em Vigilância Sanitária, Atenção Farmacêutica e Farmacologia, Analista em Ciência e Tecnologia do CNPq, Orcid: https://orcid.org/0000-00032928-4994, e-mail: carol.gomes@gmail.com.

3 Doutora em Educação em Ciências pela UFRGS, Orcid: https://orcid.org/0000-0001-6669-1789, e-mail: luciana.calabro@ufrgs.br.
} 


\section{Introdução}

O Programa Pesquisa para o SUS: gestão compartilhada em saúde (PPSUS) é uma das iniciativas do governo federal, em parceria com os governos estaduais, que contribuiu para o processo de descentralização das ações de fomento em Ciência, Tecnologia e Inovação no Brasil (BRASIL, 2014). Fomento, no sentido amplo, corresponde a políticas e programas voltados para a promoção das atividades de Ciência, Tecnologia e Inovação de instituições científicas e tecnológicas (ICT) e empresas com base em alguns instrumentos, entre os quais está a definição de contrapartidas (CGEE, 2010). Já a descentralização refere-se à distribuição de funções entre diferentes níveis de governo (federal, estadual e municipal) e entre esses e instituições do setor privado. Esse conceito incorpora duas dimensões analíticas: a descentralização de responsabilidade pela execução das políticas ou programas e a descentralização da autoridade decisória sobre essas políticas (CGEE, 2010).

O PPSUS foi criado pelo Ministério da Saúde, em 2004, como mecanismo alinhado à Política Nacional de Ciência, Tecnologia e Inovação em Saúde (PNCTIS) cuja finalidade é a superação das desigualdades regionais na área de Ciência, Tecnologia e Inovação e saúde e, para operacionalizá-lo, de forma descentralizada, conta com o Conselho Nacional de Desenvolvimento Científico e Tecnológico $(\mathrm{CNPq})$ e com as Fundações de Amparo à Pesquisa (FAP) (BRASIL, 2014).

O convênio é o instrumento utilizado pelo CNPq para repassar o recurso financeiro federal para as Fundações e a contrapartida financeira dos estados é obrigatória. A responsabilidade pela execução do PPSUS é da FAP, em consonância com as Diretrizes Técnicas do Programa (BRASIL, 2014). Já em relação à autoridade decisória, o PPSUS propõe uma gestão compartilhada entre Ministério da Saúde, CNPq, FAP e Secretaria Estadual de Saúde, onde cada parceiro possui suas responsabilidades definidas nas Diretrizes e não há uma hierarquia.

Em 2019, o Ministério da Saúde instituiu oficialmente o PPSUS por meio da Portaria 3.020, de 19 de novembro de 2019, a qual estabeleceu os seguintes objetivos para o Programa: I - apoiar financeiramente o desenvolvimento de pesquisas científicas, tecnológicas e/ou de inovação que objetivem contribuir para a resolução de problemas de saúde da população dos Estados e do Distrito Federal e para o fortalecimento da gestão do SUS; II - promover a aproximação dos sistemas de saúde com os de ciência e tecnologia locais; e III - reduzir as desigualdades regionais no campo da ciência, tecnologia e inovação em saúde no país (BRASIL, 2019). O PPSUS, é, portanto, uma política que vem sendo fortalecida e continuada pelo Ministério da Saúde. O Programa conta com 07 edições (2004; 2006; 2008; 2011; 2012; 2015-2016-2017 e 2020), sendo que a última foi iniciada em julho/2020 (CNPq, 2020).

Esta pesquisa teve por objetivos realizar uma avaliação normativa do PPSUS, no âmbito do CNPq, e estimar o seu grau de implantação. Por meio desse tipo de avaliação, verifica-se a conformidade dos componentes de uma intervenção em relação a referências, comparando-se o que foi executado com o que havia sido previsto. Ao saber em que medida o PPSUS está sendo adequadamente implantado neste órgão federal, por meio da aferição do grau de implantação, os resultados poderão influenciar a gestão deste e de outros programas de fomento descentralizado sob responsabilidade desta agência de fomento, propondo melhorias/correções em sua forma de atuação e assim subsidiar os gestores em suas decisões. 


\section{Metodologia}

Realizou-se uma avaliação normativa, definida por Contandriopoulos et al (1997) como uma atividade que consiste em fazer um julgamento sobre uma intervenção, comparando os recursos empregados e sua organização (estrutura), os serviços ou bens produzidos (processo) e os resultados obtidos, com critérios e normas. Os critérios e normas utilizados foram derivados dos documentos oficiais do PPSUS e da legislação relacionada a convênios, utilizada no CNPq para executar o programa e validados por meio de técnica de consenso entre especialistas.

A avaliação normativa considera em seu desenvolvimento, a abordagem sistêmica proposta por Donabedian (1966) utilizando-se a tríade: estrutura processo e resultados (SAMICO, FIGUEIRÓ e FRIAS, 2010). Para esta avaliação, foi verificada a fidelidade ou conformidade. Na averiguação de tal quesito, em avaliação normativa, analisam-se a estrutura e os processos, a fim de se determinar se os meios e atividades inicialmente previstos se desenrolaram tal qual haviam sido planejados (CHAMPAGNE et al, 2011a).

Foi realizado um estudo de caso único, já que esta estratégia tem um lugar diferenciado na pesquisa de avaliação e pode ser utilizada para descrever uma intervenção e o contexto da vida real no qual ela ocorreu, além de possibilitar a observação de comportamentos e processos organizacionais em vários níveis (YIN, 2015). Nesta pesquisa, o caso é o PPSUS e a unidade de análise foi o CNPq.

\subsection{Fases do processo avaliativo}

As fases do processo avaliativo foram: modelização da intervenção PPSUS, elaboração da matriz de julgamento, validação da matriz de julgamento, coleta de dados e classificação do grau de implantação, conforme detalhado a seguir:

\subsubsection{Modelização da intervenção PPSUS}

Antes de iniciar uma avaliação é preciso modelizá-la. A modelização da intervenção (PPSUS) foi uma etapa essencial para iniciar a análise e permitiu apreciar a diferença entre o que está previsto e que de fato está implantado. A modelização utilizada foi composta por três modelos principais: i) o modelo lógico causal: representa o problema a ser corrigido e suas causas; ii) o modelo lógico teórico: representa o encadeamento lógico presumido entre os objetivos de produção e os objetivos finais; e iii) modelo lógico operacional: estabelece o vínculo entre as estruturas e os processos, e isso até o primeiro resultado, ou mudança processada, seguindo o proposto por CHAMPAGNE et al (2011b).

Para a modelização, foram utilizados documentos do Ministério da Saúde: Documento de Diretrizes Técnicas do PPSUS, Portaria 3.020, que institui o Programa Pesquisa para o SUS: gestão compartilhada em saúde - PPSUS, bem como legislação aplicada a convênios e o Marco Legal de Ciência, Tecnologia e Inovação: Decreto 9.283, de 07 de fevereiro de 2018. A necessidade de escolha dos documentos institucionais do Ministério da Saúde e da legislação aplicada a convênios e o Marco Legal, deveu-se ao fato do CNPq utilizar as atividades atribuídas como de sua responsabilidade em tais documentos. A figura 01 detalha a Modelização do PPSUS. 


\subsubsection{Elaboração da matriz de julgamento}

Segundo Alves et al (2010), o estabelecimento de critérios/indicadores e parâmetros ou padrões é condição necessária para a avaliação, pois são esses quesitos que permitirão não apenas descrever um programa, como também realizar um julgamento sobre o objeto da avaliação. Tais informações podem estar dispostas numa matriz e podem incluir informações qualitativas ou numéricas.

Durante a construção da matriz, procurou-se descrever as atividades descritas na modelização e foram considerados dois componentes: estrutura e processo, foco da apreciação da fidelidade ou conformidade. A modelização, ainda, subsidiou a construção de critérios/indicadores que compuseram a matriz de julgamento, a qual contemplou os critérios/indicadores relacionados à competência de natureza técnica envolvida na gestão do PPSUS no CNPq.

\subsubsection{Validação da matriz de julgamento}

A matriz contendo os critérios/indicadores e parâmetros foram submetidos à apreciação por especialistas no $\mathrm{CNPq}$ para validação por meio de uma técnica de consenso. Foram escolhidos 04 (quatro) servidores com experiência em gestão do PPSUS, sendo que um deles possui experiência na avaliação do programa.

Neste estudo foi utilizada a Conferência de Consenso, proposta por Souza, Vieira-daSilva e Hartz, 2005. Esta técnica busca conciliar a possibilidade de discussão aberta entre os especialistas e a preservação do anonimato dos participantes, dentro de uma logística viável e possui três etapas.

Na primeira etapa, os especialistas foram solicitados a manifestar individualmente a sua concordância ou discordância com a proposta de matriz preliminar, enviada por correio eletrônico. Cada especialista poderia atribuir uma nota de zero a dez aos critérios/indicadores para os componentes estrutura e processo e poderiam sugerir exclusão, inclusão ou modificação dos critérios/indicadores. A nota representaria a importância do critério/indicador para o especialista: dez significava que o critério/indicador era de mais alta importância e zero, porém, significava sua exclusão. Todos os especialistas retornaram com suas sugestões, e as respostas foram consolidadas pela avaliadora, preservando o anonimato dos respondentes.

$\mathrm{Na}$ segunda etapa, realizou-se uma reunião via videoconferência no dia 19 de junho de 2020, em razão da pandemia de COVID-19, com o grupo de especialistas. A modelização do PPSUS e a matriz com a consolidação das respostas foram apresentadas e foi possível uma discussão sobre os documentos apresentados, além de ter sido uma oportunidade de construir o início de uma cultura avaliativa no $\mathrm{CNPq}$ de forma participativa. Ao final da reunião, foi obtida a versão final da modelização do PPSUS e uma nova matriz de julgamento, que incorporava as sugestões dos especialistas, foi construída.

Por fim, na terceira e última etapa da Conferência de Consenso, a nova matriz foi reenviada aos especialistas e foi solicitada a manifestação final sobre os critérios/indicadores. Os participantes poderiam manter as mesmas notas ou modificá-las após a discussão ocorrida de forma virtual. O sistema de pontuação permanecia o mesmo. Conforme preconizado nessa técnica, o anonimato dos respondentes foi preservado na primeira e na terceira etapa.

Após o recebimento das respostas desta última etapa, foram calculados a média aritmética e o desvio-padrão para todos os critérios/indicadores. Quanto maior a média aritmética, maior a importância do critério e o desvio-padrão permitiu a estimativa do grau de 
consenso. Os valores adotados para a seleção dos critérios/indicadores para compor a matriz de julgamento final foi de acordo com a metodologia proposta por Souza, Vieira-da-Silva e Hartz (2005):

a) Todo critério/indicador com média igual ou superior a sete foi considerado como importante. Abaixo disso, seria pouco importante, não devendo fazer parte da matriz de julgamento.

b) Todo critério/indicador com desvio-padrão inferior a três foi considerado consensual. Caso fosse também importante, o critério/indicador deveria ser incluído na matriz de julgamento.

c) Os critérios/indicadores com média igual ou superior a sete e desvio-padrão igual ou superior a três, apesar de importantes, não deveriam compor a matriz de julgamento, pois não seriam consensuais.

A matriz de julgamento contendo os critérios/indicadores finais foram incluídos os elementos propostos por Alves et al (2010), conforme Figura 02.

\subsubsection{Coleta de dados}

As técnicas de coletas de dados utilizadas para pontuar a matriz foram análise documental e observação participante, mediante diário de campo.

A coleta foi realizada entre setembro e outubro de 2020. Para análise documental foram verificados os convênios referentes às Edições 2004 a 2015-2016-2017, pareceres técnicos, relatórios de visitas e viagens, relatórios de prestação de contas dos instrumentos celebrados entre o CNPq e o Ministério da Saúde, bem como os documentos constitutivos do PPSUS e a legislação aplicada às Edições analisadas. A edição recente iniciada em 2020 foi descartada, pois apresenta alterações consideráveis tanto em relação às mudanças ocorridas na legislação de convênios, como na etapa de julgamento, pois o Ministério incluiu uma nova etapa em 2020, denominada "Comissão de Avaliação Presencial", sem participação do CNPq. Durante a realização desse estudo, as Fundações ainda estavam em fase de elaboração das minutas das Chamadas.

\subsubsection{Classificação do grau de implantação}

Para o cálculo do grau de implantação, foram utilizados os dados da avaliação normativa referente aos indicadores/critérios de estrutura e processo. Foram arbitrados os valores máximos de 380 e 120 pontos, para os componentes estrutura e processo, totalizando 500 pontos. Considerou-se uma maior importância do componente processo e, por isso, cada critério/indicador recebeu pontuação máxima de 20 pontos, enquanto os do componente estrutura receberam pontuação máxima de 10 pontos. A partir de seu preenchimento e pontuação, foi possível verificar o grau de implantação do PPSUS no CNPq. Adotou-se o julgamento em três estratos proposto por Alves et al (2010), a saber: de 66,6\% a 100\%= implantação satisfatória ou plena; de 33,3\% a > 66,6\% = implantação parcial média e de $1 \%$ a $>33,3 \%$ = implantação incipiente. O grau de implantação total foi baseado no somatório dos valores obtidos pelos critérios/indicadores dos componentes estrutura e processo divididos pelo valor máximo possível (500) X 100. 


\section{Resultados}

A Figura 01 apresenta o resultado da modelização da intervenção PPSUS, primeira fase do processo avaliativo. Os resultados obtidos após a coleta de dados estão descritos na Figura 02. Esta Figura detalha o conjunto de critérios/indicadores e estrutura e processo utilizados na aferição do grau de implantação do PPSUS e as pontuações máximas esperadas e as alcançadas, incluindo a classificação do grau de implantação.

Figura 1 - Modelização da Intervenção Programa Pesquisa para o SUS: gestão compartilhada em saúde (PPSUS) Modelização da Intervenção Programa Pesquisa para o SUS: gestão compartilhada em Saúde (PPSUS)

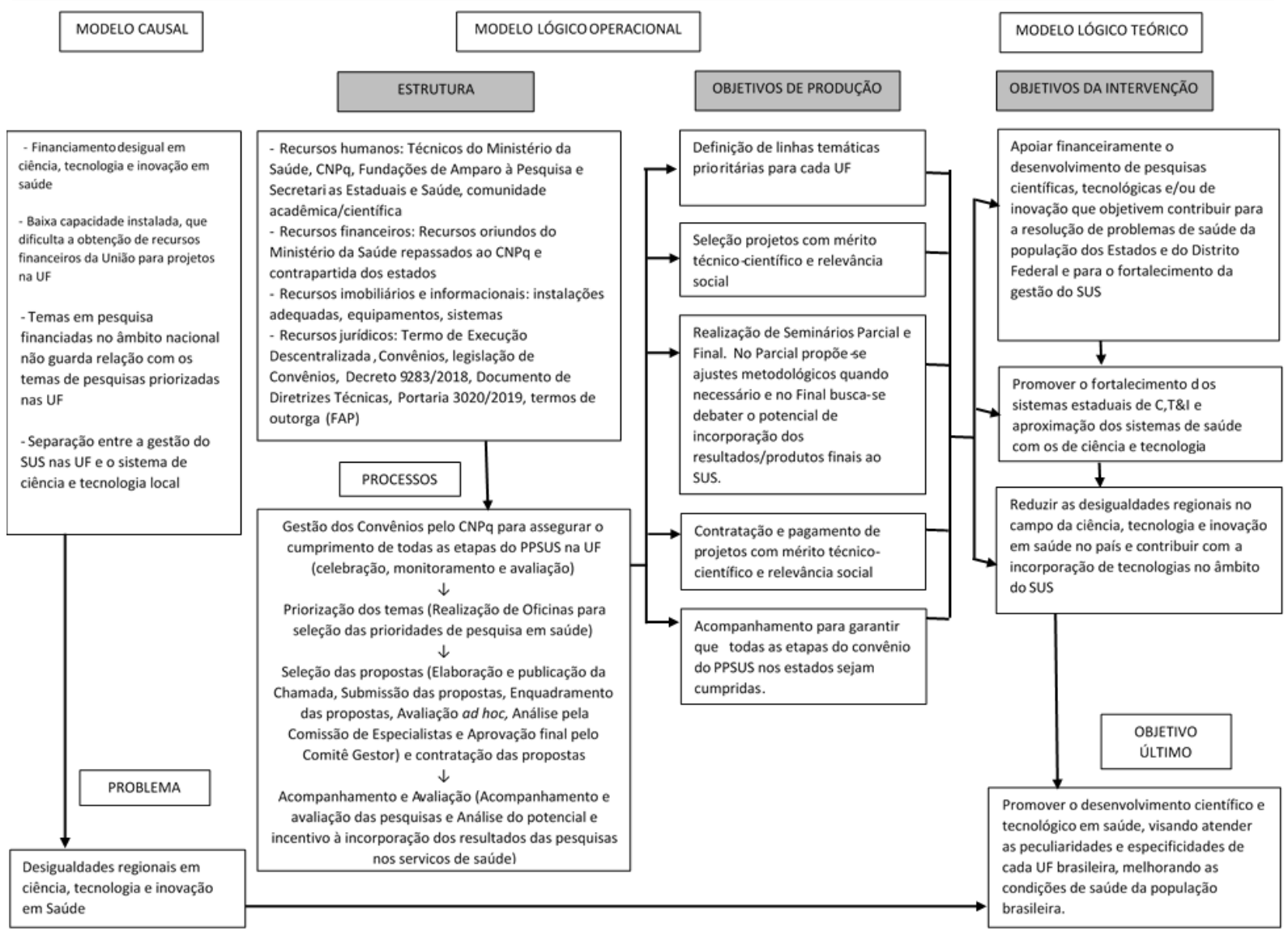

Fonte: Elaborado pelos autores, 2020. 
Figura 02 - Matriz de Julgamento Programa de Pesquisa para o SUS: gestão compartilhada em saúde

\begin{tabular}{|c|c|c|c|c|c|c|c|}
\hline $\begin{array}{l}\text { Componente } \\
\text { Processo }\end{array}$ & Critério/Indicador & Padrão & $\begin{array}{l}\text { Valor } \\
\text { máximo } \\
\text { esperado } \\
= \\
380\end{array}$ & $\begin{array}{l}\text { Descrição } \\
\text { do valor } \\
\text { ou ponto } \\
\text { de corte }\end{array}$ & Observado & $\begin{array}{l}\text { Valor } \\
\text { alcançado } \\
\text { (atribuído a } \\
\text { partir do } \\
\text { observado) }\end{array}$ & $\begin{array}{l}\text { Julgamento } \\
\text { de acordo } \\
\text { com o valor } \\
\text { atribuído }\end{array}$ \\
\hline \multirow{10}{*}{ Gestão de Convênios } & $\begin{array}{l}\text { Fornecimento de informações, a qualquer tempo, quando } \\
\text { solicitado por qualquer membro do Comitê Gestor }\end{array}$ & $\operatorname{sim}$ & 20 & $\begin{array}{l}20, \text { se sim; } \\
0, \text { se não }\end{array}$ & $\operatorname{sim}$ & 20 & \multirow{10}{*}{$\begin{array}{c}\text { de } 66,6 \% \text { a } \\
100 \%= \\
\text { implantação } \\
\text { satisfatória } \\
\text { ou plena; de } \\
33,3 \% \text { a > } \\
66,6 \%= \\
\text { implantação } \\
\text { parcial, } \\
\text { média e de } \\
1 \% \text { a > } \\
33,3 \%= \\
\text { implantação } \\
\text { incipiente. }\end{array}$} \\
\hline & $\begin{array}{l}\text { Monitoramento da execução do desembolso do TED } \\
\text { celebrado com o Ministério da Saúde }\end{array}$ & $\operatorname{sim}$ & 0 & $\begin{array}{l}20, \text { se sim; } \\
0, \text { se não }\end{array}$ & não & 0 & \\
\hline & $\begin{array}{l}\text { Gerenciamento e Repasse dos recursos dos convênios às } \\
\text { FAP }\end{array}$ & $\operatorname{sim}$ & 20 & $\begin{array}{l}20, \text { se sim; } \\
0, \text { se não }\end{array}$ & $\operatorname{sim}$ & 20 & \\
\hline & $\begin{array}{l}\text { Solicitação às FAP de informações necessárias ao } \\
\text { monitoramento da execução técnica e financeira dos } \\
\text { convênios }\end{array}$ & $\operatorname{sim}$ & 20 & $\begin{array}{l}\text { 20, se sim; } \\
0, \text { se não }\end{array}$ & $\operatorname{sim}$ & 20 & \\
\hline & $\begin{array}{c}\text { Dar conhecimento ao DECIT, quando demandado, sobre } \\
\text { as informações relacionadas ao acompanhamento da } \\
\text { execução técnica e financeira dos convênios }\end{array}$ & $\operatorname{sim}$ & 20 & $\begin{array}{l}\text { 20, se sim; } \\
0, \text { se não }\end{array}$ & $\operatorname{sim}$ & 20 & \\
\hline & $\begin{array}{c}\text { Acompanhamento da liberação e execução dos recursos } \\
\text { financeiros das FAPS aos pesquisadores/instituições } \\
\text { selecionados }\end{array}$ & $\operatorname{sim}$ & 20 & $\begin{array}{l}\text { 20, se sim; } \\
0, \text { se não }\end{array}$ & $\operatorname{sim}$ & 20 & \\
\hline & $\begin{array}{c}\text { Existência de mecanismos e estrutura no CNPq que } \\
\text { asseguram o cumprimento dos planos de trabalho dos } \\
\text { convênios }\end{array}$ & $\operatorname{sim}$ & 20 & $\begin{array}{l}\text { 20, se sim; } \\
0, \text { se não }\end{array}$ & $\operatorname{sim}$ & 20 & \\
\hline & $\begin{array}{l}\text { Verificação, ao analisar o relatório técnico final do } \\
\text { convênio, se todas as etapas do Programa foram realizadas }\end{array}$ & $\operatorname{sim}$ & 20 & $\begin{array}{l}\text { 20, se sim; } \\
0, \text { se não }\end{array}$ & $\operatorname{sim}$ & 20 & \\
\hline & Realização de visitas técnicas às FAPs & $\operatorname{sim}$ & 20 & $\begin{array}{l}20, \text { se sim; } \\
0, \text { se não }\end{array}$ & $\operatorname{sim}$ & 20 & \\
\hline & $\begin{array}{c}\text { Existência de um gestor responsável pelo monitoramento } \\
\text { do convênio e se este é formalmente designado como } \\
\text { responsável para o acompanhamento e devidamente } \\
\text { registrado na Plataforma Mais Brasil } \\
\text { para cada convênio celebrado }\end{array}$ & $\operatorname{sim}$ & 20 & $\begin{array}{l}\text { 20, se sim; } \\
0, \text { se não }\end{array}$ & não & 0 & \\
\hline
\end{tabular}




\begin{tabular}{|c|c|c|c|c|c|c|c|}
\hline $\begin{array}{c}\text { Componente } \\
\text { Processo (continuação) }\end{array}$ & Critério/Indicador & Padrão & $\begin{array}{c}\text { Valor } \\
\text { máximo } \\
\text { esperado } \\
= \\
380 \\
\end{array}$ & $\begin{array}{l}\text { Descrição } \\
\text { do valor } \\
\text { ou ponto } \\
\text { de corte }\end{array}$ & Observado & $\begin{array}{c}\text { Valor } \\
\text { alcançado } \\
\text { (atribuído a } \\
\text { partir do } \\
\text { observado) } \\
\end{array}$ & $\begin{array}{l}\text { Julgamento } \\
\text { de acordo } \\
\text { com o valor } \\
\text { atribuído }\end{array}$ \\
\hline \multirow{6}{*}{$\begin{array}{c}\text { Seleção das propostas } \\
\text { (Elaboração e publicação } \\
\text { da Chamada, Submissão } \\
\text { das propostas, } \\
\text { Enquadramento das } \\
\text { propostas, Avaliação ad } \\
\text { hoc, Análise pela } \\
\text { Comissão de } \\
\text { Especialistas e } \\
\text { Aprovação final pelo } \\
\text { Comitê Gestor) }\end{array}$} & $\begin{array}{c}\text { Aprovação, em conjunto com o DECIT, do conteúdo das } \\
\text { Chamadas elaboradas pelas FAP e SES, nos termos de } \\
\text { suas normas, políticas e regulamentos }\end{array}$ & $\operatorname{sim}$ & 20 & $\begin{array}{l}\text { 20, se sim; } \\
0, \text { se não }\end{array}$ & $\operatorname{sim}$ & 20 & \\
\hline & $\begin{array}{c}\text { Verificação se as linhas temáticas da Chamada foram } \\
\text { definidas com base no resultado da Oficina de Prioridades, } \\
\text { realizadas previamente }\end{array}$ & $\operatorname{sim}$ & 20 & $\begin{array}{l}20, \text { se sim; } \\
0, \text { se não }\end{array}$ & $\operatorname{sim}$ & 20 & \\
\hline & $\begin{array}{c}\text { Participação de representante do CNPq no CG, o qual } \\
\text { participará das atividades relacionadas à seleção e } \\
\text { acompanhamento das pesquisas }\end{array}$ & $\operatorname{sim}$ & 20 & $\begin{array}{l}\text { 20, se sim; } \\
0, \text { se não }\end{array}$ & $\operatorname{sim}$ & 20 & \\
\hline & $\begin{array}{l}\text { Monitoramento do processo de seleção de projetos em } \\
\text { análise }\end{array}$ & $\operatorname{sim}$ & 20 & $\begin{array}{l}20, \text { se sim; } \\
0, \text { se não }\end{array}$ & $\operatorname{sim}$ & 20 & \\
\hline & $\begin{array}{l}\text { Existência de registros da análise dos critérios de } \\
\text { relevância social dos projetos pelo Comitê Gestor }\end{array}$ & $\operatorname{sim}$ & 20 & $\begin{array}{l}20, \text { se sim; } \\
0, \text { se não }\end{array}$ & não & 0 & \\
\hline & $\begin{array}{l}\text { Existência de registros da análise orçamentária dos } \\
\text { projetos pelo Comitê Gestor }\end{array}$ & $\operatorname{sim}$ & 20 & $\begin{array}{l}20, \text { se sim; } \\
0, \text { se não }\end{array}$ & $\operatorname{sim}$ & 20 & \\
\hline \multirow{3}{*}{$\begin{array}{c}\text { Acompanhamento e } \\
\text { Avaliação } \\
\text { (Acompanhamento e } \\
\text { avaliação das pesquisas e } \\
\text { Análise do potencial e } \\
\text { incentivo à incorporação } \\
\text { dos resultados das } \\
\text { pesquisas nos serviços de } \\
\text { saúde) }\end{array}$} & $\begin{array}{l}\text { Participação em todos os seminários finais estaduais de } \\
\text { acompanhamento e avaliação dos projetos }\end{array}$ & $\operatorname{sim}$ & 20 & $\begin{array}{l}20, \text { se sim; } \\
0, \text { se não }\end{array}$ & $\operatorname{sim}$ & 20 & \\
\hline & $\begin{array}{l}\text { Interação entre pesquisadores e SES por meio da } \\
\text { realização dos Seminários }\end{array}$ & $\operatorname{sim}$ & 20 & $\begin{array}{l}\text { 20, se sim; } \\
0, \text { se não }\end{array}$ & $\operatorname{sim}$ & 20 & \\
\hline & $\begin{array}{c}\text { Participação nos seminários de A \& A* do DECIT quando } \\
\text { houver }\end{array}$ & $\operatorname{sim}$ & 20 & $\begin{array}{l}\text { 20, se sim; } \\
0, \text { se não }\end{array}$ & $\operatorname{sim}$ & 20 & \\
\hline $\begin{array}{l}\text { TOTAL } \\
\text { COMPONENTE } \\
\text { PROCESSO } \\
\end{array}$ & \multicolumn{7}{|c|}{ Total: $320 / 380 \times 100=84,21 \%$} \\
\hline
\end{tabular}




\begin{tabular}{|c|c|c|c|c|c|c|c|}
\hline $\begin{array}{l}\text { Componente } \\
\text { Estrutura }\end{array}$ & Critério/Indicador & Padrão & $\begin{array}{c}\text { Valor } \\
\text { máximo } \\
\text { esperado } \\
= \\
120 \\
\end{array}$ & $\begin{array}{l}\text { Descrição } \\
\text { do valor } \\
\text { ou ponto } \\
\text { de corte }\end{array}$ & Observado & $\begin{array}{c}\text { Valor } \\
\text { alcançado } \\
\text { (atribuído a } \\
\text { partir do } \\
\text { observado) } \\
\end{array}$ & $\begin{array}{c}\text { Julgamento } \\
\text { de acordo } \\
\text { com o valor } \\
\text { atribuído }\end{array}$ \\
\hline \multirow{2}{*}{ Recursos Humanos } & $\begin{array}{c}\text { Existência de servidores efetivos são responsáveis } \\
\text { pela gestão do PPSUS }\end{array}$ & $\operatorname{sim}$ & 10 & $\begin{array}{l}\text { 10, se sim; } \\
0 \text { se não }\end{array}$ & $\operatorname{sim}$ & 10 & \multirow{12}{*}{$\begin{array}{c}\text { de } 66,6 \% \text { a } \\
100 \%= \\
\text { implantação } \\
\text { satisfatória } \\
\text { ou plena; de } \\
33,3 \% \text { a > } \\
66,6 \%= \\
\text { implantação } \\
\text { parcial, } \\
\text { média e de } \\
1 \% \text { a > } \\
33,3 \%= \\
\text { implantação } \\
\text { incipiente. }\end{array}$} \\
\hline & $\begin{array}{l}\text { Proporção de convênios por número de servidores é } \\
\text { adequada }\end{array}$ & $\operatorname{sim}$ & 10 & $\begin{array}{l}10, \text { se sim; } \\
0, \text { se não }\end{array}$ & não & 0 & \\
\hline \multirow{2}{*}{ Recursos Financeiros } & $\begin{array}{l}\text { Regularidade de transferência do recurso do PPSUS } \\
\text { pelo Fundo Nacional de Saúde }\end{array}$ & $\operatorname{sim}$ & 10 & $\begin{array}{l}10, \text { se sim; } \\
0, \text { se não }\end{array}$ & $\operatorname{sim}$ & 10 & \\
\hline & $\begin{array}{l}\text { Disponibilidade de recurso recebido do FNS para } \\
\text { realização de atividades de acompanhamento }\end{array}$ & $\operatorname{sim}$ & 10 & $\begin{array}{l}10, \text { se sim; } \\
0, \text { se não }\end{array}$ & $\operatorname{sim}$ & 10 & \\
\hline \multirow{4}{*}{$\begin{array}{l}\text { Recursos imobiliários e } \\
\text { informacionais }\end{array}$} & Adequação da Estrutura física & $\operatorname{sim}$ & 10 & $\begin{array}{l}\text { 10, se sim; } \\
0, \text { se não }\end{array}$ & $\operatorname{sim}$ & 10 & \\
\hline & Adequação dos Equipamentos & $\operatorname{sim}$ & 10 & $\begin{array}{l}\text { 10, se sim; } \\
0, \text { se não }\end{array}$ & $\operatorname{sim}$ & 10 & \\
\hline & $\begin{array}{l}\text { Existência de um instrumento informatizado de } \\
\text { monitoramento dos convênios no CNPq }\end{array}$ & $\operatorname{sim}$ & 10 & $\begin{array}{l}10, \text { se sim; } \\
0, \text { se não }\end{array}$ & não & 0 & \\
\hline & $\begin{array}{l}\text { Utilização da Plataforma Mais Brasil para gestão e } \\
\text { acompanhamento dos convênios }\end{array}$ & $\operatorname{sim}$ & 10 & $\begin{array}{l}10, \text { se sim; } \\
0, \text { se não }\end{array}$ & $\operatorname{sim}$ & 10 & \\
\hline \multirow{4}{*}{ Recursos jurídicos } & Existência de normas específicas para o PPSUS & $\operatorname{sim}$ & 10 & $\begin{array}{l}10, \text { se sim; } \\
0, \text { se não }\end{array}$ & $\operatorname{sim}$ & 10 & \\
\hline & $\begin{array}{c}\text { Incorporação de normas específicas do PPSUS nos } \\
\text { convênios celebrados com as FAP }\end{array}$ & $\operatorname{sim}$ & 10 & $\begin{array}{l}10, \text { se sim; } \\
0, \text { se não }\end{array}$ & $\operatorname{sim}$ & 10 & \\
\hline & $\begin{array}{l}\text { Existência de norma específica no CNPq sobre gestão } \\
\text { dos convênios }\end{array}$ & $\operatorname{sim}$ & 10 & $\begin{array}{l}10, \text { se sim; } \\
0, \text { se não }\end{array}$ & não & 0 & \\
\hline & $\begin{array}{l}\text { Adequação do Decreto 9283/2018 aos convênios } \\
\text { celebrados no âmbito do PPSUS }\end{array}$ & $\operatorname{sim}$ & 10 & $\begin{array}{l}10, \text { se sim; } \\
0, \text { se não }\end{array}$ & não & 0 & \\
\hline $\begin{array}{l}\text { TOTAL COMPONENTE } \\
\text { ESTRUTURA } \\
\end{array}$ & \multicolumn{7}{|c|}{ Total: $80 / 120$ x 100: $66,66 \%$} \\
\hline $\begin{array}{c}\text { GRAU DE } \\
\text { IMPLANTAÇÃO TOTAL }\end{array}$ & \multicolumn{7}{|c|}{ GI total: $320+80 / 500 \times 100=80 \%$} \\
\hline
\end{tabular}

Fonte: Elaborado pelos autores, 2020. 


\section{Discussão}

Verificou-se que o grau de implantação obtido, por componente, foi de $66,66 \%$ e $84,21 \%$ para estrutura e processo, respectivamente. O grau de implantação total, contudo, considerando o somatório da pontuação obtida por componente, foi de $80 \%$, percentual classificado como "implantação satisfatória ou plena".

Deve ser dado especial atenção ao componente estrutura, pois o valor alcançando de $66,6 \%$ é o limite entre a classificação "satisfatória ou plena" e a "parcial, média", mostrando a necessidade de se investir na melhoria das condições de trabalho dos profissionais do CNPq. Os pontos a serem revistos, os quais receberam a menor pontuação, são os em relação a proporção de convênios por servidor, ausência de um instrumento informatizado de monitoramento dos convênios no $\mathrm{CNPq}$, inexistência de norma específica no $\mathrm{CNPq}$ sobre gestão dos convênios e inadequação do Decreto 9283/2018 aos convênios celebrados no âmbito do PPSUS.

Não foi encontrado normativo que estabeleça o número de convênios a serem acompanhados por servidor, porém, tendo em vista a existência de outras ações a serem acompanhadas pelas mesmas pessoas, sugere-se uma negociação prévia entre os envolvidos.

A elaboração de uma norma específica interna para a gestão de convênios no CNPq padronizaria os procedimentos realizados pelas duas coordenações técnicas envolvidas, a saber Coordenação Geral de Cooperação Nacional e Coordenação Geral do Programa de Pesquisa em Saúde. O PPSUS está sob responsabilidade desta última. Verificou-se que os procedimentos de monitoramento divergem de uma coordenação para outra, assim como em alguns ritos processuais. A existência de um instrumento informatizado para o monitoramento dos convênios no $\mathrm{CNPq}$ contribuiria com essa padronização das atividades entre as diversas áreas, visto que foi observado que cada coordenação tem procedimentos próprios, sendo muitas vezes de iniciativas dos próprios servidores e não da instituição.

Outro ponto que merece ser pauta de discussão entre as instâncias superiores do CNPq é a inadequação do Decreto 9283/2018 às parcerias entre o CNPq e as agências de fomento. O Decreto prevê a parceria, mas é omisso em detalhá-la, fazendo que seja adotada a legislação de convênios aplicadas a todos os órgãos do governo federal.

Já no componente processo, apesar de apresentar o grau de implantação de 84,21\%, verificou-se que o monitoramento da execução do desembolso do Termo de Execução Descentralizada (TED) celebrado com o Ministério da Saúde merece atenção. O CNPq não dispõe de um setor específico para supervisão da execução do TED e as áreas técnicas não têm pessoal e até mesmo conhecimento para monitorar de forma mais pormenorizada e efetiva os TEDs celebrados entre o CNPq e o Ministério da Saúde e outros órgãos.

Quanto à existência de um gestor responsável pelo monitoramento do convênio e se este é formalmente designado como responsável para o acompanhamento e devidamente registrado na Plataforma Mais Brasil para cada convênio celebrado, verificou-se que apesar da legislação prevê isto desde a Portaria Interministerial 127/2008 e a exigência ser mantida nas Portarias subsequentes: 507/2011 e 424/2016, não há servidor formalmente designado e registrado na Plataforma Mais Brasil para cada convênio nas Edições analisadas. Contudo, esta exigência foi obedecida para os convênios celebrados no âmbito da Portaria 424/2016, que foram descartados por serem da edição 2020.

Até aqui, todos os pontos discutidos estão relacionados à atuação do CNPq na gestão de convênios, considerando as suas obrigações na figura de concedente, o que se aplicaria a todos 
os demais programas e não somente o PPSUS. Em relação às obrigações do CNPq previstas nas diretrizes, merece atenção à sua atuação como membro do comitê gestor.

Segundo o documento de Diretrizes Técnicas, o principal objetivo do comitê gestor é a análise de relevância social e orçamentária dos projetos já avaliados pelos pareceristas ad hoc e comissão de especialistas. Além disso, definiu-se que para a análise de relevância social, deverão ser considerados os seguintes aspectos: 1. Contribuição para a superação das desigualdades estatuais/regionais no âmbito da atenção à saúde; 2. Melhoria dos indicadores de saúde na região; 3. Impacto positivo nas condições de saúde e/ou na qualidade de vida da população; 4. Consonância com a situação de morbimortalidade relacionada ao agravo a ser pesquisado; 5. Capacidade de respostas às lacunas de conhecimento sobre o tema; consonância com a Política Nacional e Estadual de Saúde; 6. Consonância com as prioridades de pesquisa em saúde da UF; 7. Clareza dos benefícios esperados e impactos (científico, tecnológico, econômico, social e ambiental) para transformação social e 8. Possibilidade de incorporação dos resultados em curto e médio prazo na gestão e/ou atenção em saúde (BRASIL, 2014).

Observou-se que não há, nas atas de julgamento do comitê gestor, nenhum registro dessa análise de relevância social dos projetos, apesar desses critérios estarem previstos nas chamadas. A discussão, nesta fase de julgamento, é muito centrada no orçamento solicitado pelo pesquisador.

Em relação à metodologia da avaliação, adotou-se na matriz o termo "critério/indicador" como sinônimo e representaria as caraterísticas a serem observadas (ALVES et al, 2010).

Adotou-se, ainda, a designação "SIM" como padrão para as respostas. A elaboração de perguntas que permitam respostas "SIM" ou "NÃO" para critérios/indicadores que não disponham de medidas quantitativas pode ser útil para responder às dimensões relacionadas aos processos administrativos e operacionais do PPSUS e análise de tais dados é pré-requisito para avaliar o seu grau de implantação (OLIVEIRA, 2008).

Os critérios/indicadores e os parâmetros foram submetidos à apreciação por especialistas no CNPq para validação por meio da Conferência de Consenso. Os processos de construção de consenso não só ampliam a possibilidade de validade dos critérios/indicadores como conferem maior legitimidade aos processos avaliativos (MEDINA et al, 2005). Não foram encontrados na literatura o número mínimo de participantes para Conferência de Consenso. O quantitativo utilizado foi justificado pelo critério utilizado na avaliação, que foi a procedência institucional.

Em relação ainda aos critérios/indicadores, percebeu-se que ao se permitir como respostas "SIM" ou "NÃO", estes poderiam ser enquadrados na definição de indicadores qualitativos de Minayo (2009), por se referirem a aspectos intangíveis da realidade, captados indiretamente, não facilmente observáveis. Ainda, segundo a autora, os indicadores assinalam tendências e nenhum indicador, seja quantitativo ou qualitativo, pode fornecer certeza absoluta quanto aos resultados de uma ação ou de um processo, pois sua função é ser um sinalizador.

Uma questão crítica que se coloca aos investigadores é o grau de confiabilidade e validade dos indicadores qualitativos. Em relação à confiabilidade, Minayo (2009) argumenta que as percepções e relações sociais, objetos desse tipo de análise são dinâmicas e impossíveis de serem repetidas em sua integralidade; são frutos do caminho interpretativo, eminentemente intersubjetivo, não cabendo falar em confiabilidade. Já para a confiabilidade externa, em que diferentes pesquisadores deveriam encontrar os mesmos resultados investigando o mesmo tema, é necessário não se esquecer que as investigações qualitativas não buscam 
homogeneidades e sim diferenciações e especificidades (MINAYO, 2009). Portanto, os critérios/indicadores utilizados, ainda que somente qualitativos, se enquadram nesses aspectos.

Além disso, a abordagem metodológica utilizada - estudo de caso único, oferece um elevado potencial de validade interna, apesar desta observação única limitar a validade externa (CHAMPAGNE et al, 2011c). Porém, nesta avaliação, não se buscou a generalização e, portanto, a escolha do estudo de caso único foi adequada.

A posição da pesquisadora como avaliadora interna não trouxe prejuízos à avaliação, pois segundo Figueiró, Frias e Navarro (2010), uma das principais características da avaliação normativa é ser normalmente realizada por pessoas diretamente envolvidas no programa, como os responsáveis pelo funcionamento e pela gestão da intervenção.

Ainda sobre avaliação normativa, concorda-se com Uchimura e Bosi (2002), que a análise de programas ou seus constituintes à luz de critérios e normas consiste sim em uma atividade científica que requer, para sua execução, determinado rigor metodológico, apesar de alguns autores afirmarem que na avaliação normativa não se recorre a métodos científicos para o julgamento de uma intervenção (CONTANDRIOPOULOS et al, 1997). Feliciano (2005) sustenta, ainda, que a avaliação normativa não representa um conhecimento acrítico, crédulo e também, neste tipo de avaliação, busca-se a validade e a confiabilidade da mensuração, atendidas neste estudo.

\section{Conclusões}

Apesar do grau de implantação total obtido (80\%), considerado "implantação satisfatória ou plena", em relação à conformidade em termos de estrutura e processos, esperavase um percentual ainda maior, já que o CNPq é partícipe do PPSUS desde 2004. Os processos relacionados à atuação do CNPq nas etapas do PPSUS de seleção de projetos, acompanhamento e avaliação, segundo as diretrizes do programa, estão consolidados, apesar do estudo sugerir um aperfeiçoamento na etapa do comitê gestor, promovendo maior transparência no registro dos critérios utilizados para o julgamento dos projetos e ampliando, assim, a discussão, hoje focada nos aspectos orçamentários.

Os processos relacionados à gestão de convênios também merecem aprimoramento, especialmente nas atividades de monitoramento do instrumento celebrado entre o CNPq e o Ministério da Saúde, pois não há um setor específico para esta ação e envolve aspectos que as coordenações técnicas não dominam.

O grau de implantação relacionado ao componente estrutura $(66,66 \%)$ no valor limite para a "implantação satisfatória ou plena" mostra a necessidade de o $\mathrm{CNPq}$ aprimorar seus instrumentos jurídicos, informacionais e de recursos humanos para uma melhor operacionalização de seus convênios. Esta observação não se aplica somente ao PPSUS, mostrando a importância da realização desta avaliação para a gestão deste e de outros programas de fomento descentralizado, propondo melhorias/correções e assim oferecer mais subsídios aos gestores em suas decisões.

A condição de avaliador interno foi benéfica, pois houve uma maior familiaridade com o tema e, para minimizar a possível parcialidade, foram utilizados roteiros para orientar a coleta de dados. Ressalta-se, ainda, que cada olhar sobre uma intervenção e sobre os resultados do estudo pode gerar interpretações diferentes, pois as experiências e expectativas de cada grupo irão trazer novos significados (ALVES et al, 2010). 
A matriz poderia, ainda, conter critérios/indicadores de caráter quantitativo, porém o uso dos critérios/indicadores propostos mostrou-se de fácil compreensão e útil para os objetivos almejados e poderá ser adaptada e aperfeiçoada periodicamente para ser utilizada na avaliação normativa de qualquer outro programa do CNPq.

\section{Referências}

ALVES, C.K.A et al. Interpretação e análise das informações: o uso de matrizes, critérios, indicadores e padrões. In: SAMICO, I. et al (org). Avaliação em Saúde bases conceituais e operacionais. Rio de Janeiro: Medbook, 2010.p. 89-107.

BRASIL. Ministério da Saúde. Secretaria de Ciência, Tecnologia e Insumos Estratégicos. Departamento de Ciência e Tecnologia. Programa Pesquisa para o SUS: gestão compartilhada em saúde - Diretrizes Técnicas. 5. ed. Brasília: Editora do Ministério da Saúde, 2014. 64 p.

BRASIL. Portaria n ${ }^{\circ} 3020$, de 19 de novembro de 2019. Altera a Portaria de Consolidação no 5/GM/MS, de28 de setembro de 2017, para instituir o Programa Pesquisa para o SUS: Gestão Compartilhada em Saúde - PPSUS. Diário Oficial da União, seção 1, Brasília, DF, ano 157, n. 227, p. 51, 25 nov. 2019.

CENTRO DE GESTÃO E ESTUDOS ESTRATÉGICOS. Descentralização do fomento à ciência, tecnologia e inovação no Brasil. Brasília: CGEE, 2010.154 p.

CHAMPAGNE, F. et al. A Apreciação Normativa. In: BROUSSELLE, A. et al (org). Avaliação: conceitos e métodos. Rio de Janeiro: FIOCRUZ, 2011a. p. 77-94.

CHAMPAGNE, F. et al. Modelizar as Intervenções. In: BROUSSELLE, A. et al (org). Avaliação: conceitos e métodos. Rio de Janeiro: FIOCRUZ, 2011b. p. 61-74.

CHAMPAGNE, F. et al. A Análise da Implantação. In: BROUSSELLE, A. et al (org). Avaliação: conceitos e métodos. Rio de Janeiro: FIOCRUZ, 2011c. p. 217-238.

CONSELHO NACIONAL DE DESENVOLVIMENTO CIENTÍFICO E TECNOLÓGICO. Relatório de Gestão 2020. Brasília: CNPq, 2020. Disponível em: https://www.gov.br/cnpq/pt-br/acesso-a-informacao/auditorias/RelatoriodeGestao2020.pdf. Acesso em: 11 maio. 2021.

CONTANDRIOPOULOS, A. et al. A avaliação na área da Saúde: conceitos e métodos. In: HARTZ, Z.M.A.(org). Avaliação em saúde: dos modelos conceituais à prática na análise da implantação de programas. Rio de Janeiro: Editora FIOCRUZ, 1997. p. 29-47.

DONABEDIAN, A. Evaluating the quality of medical care. Milbank Memorial Fund, v. 44, n. 3, p. 166-206, 1966.

FELICIANO, K.V.O. A relação entre o avaliador e o objeto avaliado. Revista Brasileira de Saúde Materno- Infantil, Recife, v. 5 (supl 1), p. 583-592, Dez. 2005. Disponível em: https://www.scielo.br/scielo.php?pid=S1519-

38292005000500009\&script=sci_abstract\&tlng=pt. Acesso em: 14 dez. 2020. 
FIGUEIRÓ, A. C.; FRIAS, P.G.; NAVARRO, L.M. Avaliação em saúde: conceitos básicos para a prática nas instituições. In: SAMICO, I. et al (org). Avaliação em Saúde bases conceituais e operacionais. Rio de Janeiro: Medbook, 2010.p. 01-13.

MEDINA,M.G. et al. Uso de modelos teóricos na avaliação em saúde: aspectos conceituais e operacionais. In: HARTZ, Z.M.A; VIEIRA-DA-SILVA, L.M.(org). Avaliação em saúde dos modelos teóricos à prática na avaliação de programas e sistemas de saúde. Salvador: EDUFBA, Rio de Janeiro: Editora FIOCRUZ, 2005. p. 41-63.

MINAYO, M.C.S. Construção de indicadores qualitativos para avaliação de mudanças. Revista Brasileira de Educação Médica, Rio de Janeiro, v. 33 (1 supl 1), p. 83-91, Jan. 2009. Disponível em: https://www.scielo.br/scielo.php?pid=S010055022009000500009\&script=sci_abstract\&tlng=pt. Acesso em: 14 dez. 2020.

MINAYO, M.C.S. Construção de indicadores qualitativos para avaliação de mudanças. Revista Brasileira de Educação Médica, Rio de Janeiro, v. 33 (1 supl 1), p. 83-91, Jan. 2009. Disponível em: https://www.scielo.br/scielo.php?pid=S010055022009000500009\&script=sci_abstract\&tlng=pt. Acesso em: 14 dez. 2020.

OLIVEIRA, M.M. Programa pesquisa para o SUS : gestão compartilhada em Saúde PPSUS : construção do modelo lógico e da matriz de medidas avaliativas. 2008. Dissertação (Mestrado em Ciências da Saúde) - Faculdade de Ciências da Saúde, Universidade de Brasília, Brasília, 2008. Disponível em: https://repositorio.unb.br/handle/10482/5231. Acesso em: 14 dez. 2020.

SAMICO, I.; FIGUEIRÓ, A.C.; FRIAS, P.G. Abordagens metodológicas na avaliação em saúde. In: SAMICO, I. et al (org). Avaliação em Saúde bases conceituais e operacionais. Rio de Janeiro: Medbook, 2010. p. 15-28.

SOUZA, L.E.P.F; VIEIRA-DA-SILVA, L.M; HARTZ, Z.M.A, Conferência de Consenso sobre a imagem-objetivo da descentralização da atenção à saúde no Brasil. In: HARTZ, Z.M.A; VIEIRA-DA-SILVA, L.M.(org). Avaliação em saúde dos modelos teóricos à prática na avaliação de programas e sistemas de saúde. Salvador: EDUFBA, Rio de Janeiro: Editora FIOCRUZ, 2005. p. 65-102.

UCHIMURA, K. Y.; BOSI, M.L.M. Qualidade e subjetividade na avaliação de programas e serviços de saúde. Cadernos de Saúde Pública, Rio de Janeiro, v. 18, n. 6, p. 1561-1569, Nov-Dez. 2002. Disponível em: https://www.scielo.br/scielo.php?script=sci_arttext\&pid=S0102-311X2002000600009. Acesso em: 14 dez. 2020.

YIN, R.K. Estudo de caso, planejamento e métodos. 5. ed. Porto Alegre: Bookman, 2015.

Recebido em janeiro de 2021.

Aprovado em maio de 2021. 